\title{
Prevalence of neonatal jaundice at a tertiary health institution in Ondo state, Nigeria
}

\author{
Matthew Idowu Olatubi ${ }^{1, A-F}{ }^{\oplus}$, Olabisi Fatimo Ibitoye ${ }^{2, A-F}{ }^{\oplus}$, Omoleye Sadibo ${ }^{3, A-C, E-F \oplus}$, \\ Oluwaseun Segun Bolarinwa ${ }^{4, A, C-D, F \oplus}$, Modupe Motunrayo Adamolekun ${ }^{5, A, C, E-F \oplus}$ \\ ${ }^{1}$ Bowen University, Iwo, Nigeria \\ ${ }^{2}$ Ondo State School of Midwifery, Akure, Nigeria \\ ${ }^{3}$ Federal Medical Centre, Nigeria \\ ${ }^{4}$ University of Medical Sciences, Ondo, Nigeria \\ ${ }^{5}$ Department of Nursing Science, University of Medical Sciences, Ondo, Nigeria \\ A - Research concept and design, B - Collection and/or assembly of data, C - Data analysis and interpretation, \\ $D$ - Writing the article, E - Critical revision of the article, F - Final approval of article
}

Matthew Idowu Olatubi, Olabisi Fatimo Ibitoye, Omoleye Sadibo, Oluwaseun Segun Bolarinwa, Modupe Motunrayo Adamolekun. Prevalence of neonatal jaundice at a tertiary health institution in Ondo state, Nigeria. J Pre-Clin Clin Res. 2019; 13(3): 114-117. doi: 10.26444/jpccr/111773

\begin{abstract}
Introduction. This study assesses the occurrence of neonatal jaundice among neonates admitted between January 2007 - December 2016 in a tertiary health institution in Ondo State, Nigeria.

Materials and method. A descriptive retrospective research design was used for the study conducted in the Neonatal Ward of a tertiary health institution in Ondo State. Data were collected using a self-structurd checklist. Ethical clearance was obtained from the hospital Ethical Committee. Data was analyzed using SPSS; both descriptive and inferential statistics were used.

Results. Results showed that a total of 715 neonates were admitted in the hospital during the period, 88 (34.2\%) were admitted on their first day of birth. There were more male neonates admitted for jaundice than female 146 (56.8\%). The highest incidence of neonatal jaundice in the hospital during the years under review occurred in 2008 (32 neonates); while the least was recorded in 2016 - 9 neonates. A total of 257 neonates were admitted for neonatal jaundice over the 10 year period under review. The serum bilirubin level reduced from $13.76 \pm 8.04$ on admission to $3.43 \pm 2.34$ at discharge. Only 61 (23.7\%) of the neonates had exchange blood transfusion performed. Also, 36 (14.0\%) neonates developed complications of neonatal jaundice, of which $25(69.4 \%)$ died from these complications.

Conclusions. A concerted effort should be made to create awareness about neonatal jaundice among women of reproductive age, and emphasis should be placed on the importance of early diagnosis and treatment of NNJ.
\end{abstract}

\section{Key words}

prevalence, neonate, jaundice

\section{INTRODUCTION}

Neonatal jaundice is a common physiological occurrence in newborns with over half of term [1] and $80 \%$ of preterm neonates $[2,3]$ showing clinical signs, including yellow discolouration of the skin and sclera resulting from high serum levels of bilirubin. Jaundice is a result of the increased breakdown of red blood cells and/or decreased hepatic excretion of bilirubin.

Of the 7.6 million deaths estimated to occur in children below the age of 5 years in 2010, $40 \%$ occurred during the neonatal period [4]. Several reports have indicated the important contribution of severe hyperbilirubinemia to neonatal morbidity and mortality $[5,6,7,8]$. Worldwide, an estimated 14.1 million newborns (10.5\% of live births) require phototherapy for jaundice; of these, 6 million do not have access to treatment and 2.4 million without access to treatment are in Central and South Asia [9]. Scrafford, et al [10] discovered that the incidence of referral for neonatal jaundice was 29.3 per 1,000 live births (95\% confidence

Address for correspondence: Matthew Idowu Olatubi, Bowen University Iwo, Nigeria

E-mail: omoolatubi@gmail.com

Received: 21.01.2019; accepted: 14.08.2019; first published: 20.09.2019 interval: 26.9, 31.7). Male gender, high birth weight, breastfeeding patterns, warm air temperature, primiparity, skilled birth attendance, place of delivery, prolonged labour, oil massage, paternal education and ethnicity were found to be significant risk factors for jaundice [10]. Current evidence, however, suggests that low- and middle-income countries (LMICs) disproportionately bear the burden of severe neonatal hyperbilirubinemia $[8,9,11]$. In a review on the global burden of jaundice, sub-Saharan Africa and South Asia were reported to be the leading contributors to an estimated 1.1million babies who would develop severe jaundice worldwide every year [9]. Another systematic review found that low and medium income countries consistently report substantially higher rates of exchange transfusion and bilirubin-induced neurologic dysfunctions (acute bilirubin encephalopathy (ABE) and chronic bilirubin encephalopathy or kernicterus) than in high-income countries [11].

In Nigeria, about $5.5 \%$ of all newborns are estimated to have clinically significant neonatal jaundice requiring phototherapy and/or exchange blood transfusion (EBT), which is probably one of the highest globally [6]. Most tertiary institutions are still overwhelmed with exceptionally high rates of EBT daily [12]. Therefore, this study assesses the prevalence of neonatal jaundice in a tertiary health institution in Ondo State, Nigeria, between January 2003 - December 2013. 


\section{OBJECTIVE}

The aim of the study was to determine the presence or absence of complications among neonates admitted for neonatal jaundice, and ascertain the survival rates of neonates diagnosed with neonatal jaundice in the hospital.

\section{MATERIALS AND METHOD}

The study adopted a descriptive retrospective design and was carried out in a tertiary health institution. The hospital also serves as referral centre for other hospitals within and outside Ondo State. The hospital provides primary, secondary and tertiary levels of health care. The hospital is an approved institution for post-graduate medical training. The hospital has 250-bed capacity with average bed occupancy of 70\%, and an average of over 5,000 patients seeking care on an out patients basis monthly. The staff strength of the hospital is about 2,000, with 355 nurses among other health professional and supporting staff.

Health institution owned by the Federal government of Nigeria. Medical records of all neonates admitted for neonatal jaundice in the hospital between January 2003 - December 2013 were retrieved and examined using a checklist. The total number of neonates admitted to the hospital during the period under review was also determined from the health records and statistics department of the hospital. Ethical permission was obtained from the institution authority, and information retrieved was handled confidentially. Data collected were analysed using Statistical Package for Social Sciences (SPSS) version 16. Both descriptive and inferential statistics were used.

\section{RESULTS}

A total of 715 neonates were admitted to the hospital during the period under review. Results showed that the mean age on admission of the neonates was $3.44 \pm 2.50$ days. Most of the neonates with neonatal jaundice in the hospital during the period under review were male $156(56.8 \%)$. The majority of the neonates -180 (70.0\%), were Yoruba and Christians (80.2\%) (Tab. 1).

The overall prevalence of neonatal jaundice was found to be $35.94 \%$ (Tab. 2). The highest prevalence was recorded in 2004 with $64.00 \%$, followed by 2015 with $52.00 \%, 2012$ with $41.67 \%$ and 2006 with $40.00 \%$. The least was recorded in 2016 (11.25\%), and 32.5\% in 2014 and 2011, respectively. Incidence of neonatal jaundice by gender showed that 146 (56.8\%) of the neonates with neonatal jaundice were male, while 111 (43.2\%) were female (Tab. 3). Males were found to be more numerous than females in eight (8) out of the ten (10) years reviewed, while females were more numerous only in 2014 and 2015.

All the neonates admitted in the hospital during the period under review were managed using drugs and phototherapy, while only $61(23.7 \%)$ had exchange blood transfusion performed. The mean weight of the neonates increased from $2.93 \pm 0.53 \mathrm{~kg}$ on admission to $3.18 \pm 0.55$ on discharge, while the packed cell volume also increased from $46.11 \pm 10.65 \%$ to $48.98 \pm 7.90 \%$. On the other hand, the mean total serum
Table 1. Socio-demographic characteristics of participants

\begin{tabular}{lccc}
\hline & & $\begin{array}{c}\text { Frequency } \\
(\mathrm{n}=257)\end{array}$ & $\begin{array}{c}\text { Percentage } \\
(\%)\end{array}$ \\
\hline Age in days at & 1 day & 88 & 34.2 \\
admission & $2-3$ & 57 & 22.2 \\
& $4-7$ & 96 & 37.4 \\
& $8-14$ & 16 & 6.2 \\
& Mean & 3.44 & \\
\hline Gender & Std Deviation & 2.50 & \\
& Range & 12.00 & 56.8 \\
\hline Ethnicity & Male & 146 & 43.2 \\
& Female & 111 & 70.0 \\
& Yoruba & 180 & 12.8 \\
& Igbo & 33 & 3.1 \\
& Hausa & 8 & 3.1 \\
& Benue & 8 & 7.8 \\
& Igbira & 20 & 1.9 \\
& Irobo & 5 & 1.2 \\
\hline Religion & ljaw & 3 & 80.2 \\
& Christianity & 206 & 19.8 \\
\hline & Islam & 51 &
\end{tabular}

Table 2. Prevalence of neonatal jaundice

\begin{tabular}{lccc}
\hline Year & $\begin{array}{c}\text { Total number of } \\
\text { neonate admitted }\end{array}$ & $\begin{array}{c}\text { Total number of } \\
\text { neonate with jaundice }\end{array}$ & Percentage \\
\hline 2007 & 78 & 26 & 33.33 \\
\hline 2008 & 50 & 32 & 64.00 \\
\hline 2009 & 72 & 26 & 36.11 \\
\hline 2010 & 75 & 30 & 40.00 \\
\hline 2011 & 80 & 26 & 32.50 \\
\hline 2012 & 72 & 30 & 41.67 \\
\hline 2013 & 78 & 26 & 33.33 \\
\hline 2014 & 80 & 26 & 32.50 \\
\hline 2015 & 50 & 26 & 52.00 \\
\hline 2016 & 80 & 9 & 11.25 \\
\hline Total & 715 & 257 & 35.94 \\
\hline
\end{tabular}

Table 3. Weight, pcked cell volume, and total serum bilirubin level of neonates

\begin{tabular}{lccc}
\hline Variable & & At Admission & Outcome \\
\hline Weight & Mean & $2.93 \pm 0.53$ & $3.18 \pm 0.55$ \\
& Range & 3.10 & 3.10 \\
& Minimum & 1.20 & 1.30 \\
& Maximum & 4.30 & 4.40 \\
\hline Packed cell volume & Mean & $46.11 \pm 10.65$ & $48.98 \pm 7.90$ \\
& Range & 64.00 & 55.00 \\
& Minimum & 11.00 & 11.00 \\
& Maximum & 75.00 & 66.00 \\
\hline Total serum & Mean & $13.76 \pm 8.04$ & $3.43 \pm 2.34$ \\
bilirubin level & Range & 47.70 & 2.34 \\
& Minimum & 1.70 & 1.00 \\
& Maximum & 49.40 & 18.20 \\
\hline
\end{tabular}

bilirubin level reduced from $13.76 \pm 8.04$ on admission to $3.43 \pm 2.34$ at discharge.

Outcome of care for the neonates showed that $36(14.0 \%)$ of them had a complication - acute bilirubin encephalopathy (kernicterus). 25 neonates with neonatal jaundice died of their condition during the period under review; the survival rate was therefore $90.27 \%$. 
Table 4. Management strategies adopted in the management of neonatal jaundice and outcomes

\begin{tabular}{|c|c|c|c|}
\hline Variables & & $\begin{array}{c}\text { Frequency } \\
(\mathrm{n}=257)\end{array}$ & $\begin{array}{c}\text { Percent } \\
(\%)\end{array}$ \\
\hline Phototherapy used & Yes & 257 & 100.0 \\
\hline Usage of drugs & Yes & 257 & 100.0 \\
\hline Exchange blood transfusion & $\begin{array}{l}\text { Yes } \\
\text { No }\end{array}$ & $\begin{array}{c}61 \\
196\end{array}$ & $\begin{array}{l}23.7 \\
76.3\end{array}$ \\
\hline $\begin{array}{l}\text { Presence of complications } \\
\text { from Neonatal jaundice }\end{array}$ & $\begin{array}{l}\text { Yes } \\
\text { No }\end{array}$ & $\begin{array}{c}36 \\
221\end{array}$ & $\begin{array}{l}14.0 \\
86.0\end{array}$ \\
\hline Mortality or survival & $\begin{array}{l}\text { Mortality } \\
\text { Survival }\end{array}$ & $\begin{array}{c}25 \\
232\end{array}$ & $\begin{array}{c}9.73 \\
90.27\end{array}$ \\
\hline
\end{tabular}

\section{DISCUSSION}

Socio-demographic characteristics of the participants revealed that only about one out of every three of the neonates were admitted on the first day of birth, while $6.2 \%$ were admitted during the second week of birth. The mean age of the neonates on admission was observed to be $3.44 \pm 2.50$.

Findings of this study showed that a number of the neonates (34.2\%) were admitted to the hospital on the day of their birth because they were preterm or with other medical conditions and neonatal jaundice on admission. This confirms the submission of Sarici et al. [1] that neonatal jaundice is a common occurrence among newborns. Therefore there is nothing strange about all the neonates being admitted within the first two weeks of birth. Results showed that one out of every three neonates (35.94\%) admitted in the hospital were admitted for neonatal jaundice during the 10 year period reviewed. This is similar to $35.0 \%$ reported earlier in the Neonatal Intensive Care Unit in a Teaching Hospital in South Eastern Nigeria [13].

The prevalence of neonatal jaundice among three major ethnic groups in Nigeria was not assessed in the current study because there were few ethnic Igbos and Hausas who participated in the study, while the majority were Yoruba. This is similar to the report by Coulter, Akpabio \& Jikeme [14], at the Emergency Paediatric Unit of the Amadu Bello University Hospital, with Kaduna among Yoruba tribes.

Scrafford et al. [10] submit that male gender is one of the predisposing factors for neonatal jaundice, this is further confirmed by the results of this study, as male were found to be more numerous among neonates admitted for neonatal jaundice than females. As a matter of fact, during the 10 year period reviewed, males were found to be more numerous among those with neonatal jaundice during eight years. Among the neonates admitted, the bilirubin level was found to be higher in females (mean 13.44 \pm 8.55 ), compared to $14.17 \pm 7.33$. However, this differences was found not to be significant $(\mathrm{p}=0.471)$.

Hyperbilirubinemia is a primary concern associated with jaundice due to the connection between increased levels of unconjugated bilirubin and the neurotoxic effects causing long-term sequelae, including cerebral palsy, hearing loss and kernicterus [3]. The aim of management is therefore to reduce the level of bilirubin in the blood. It was therefore not unexpected that the mean bilirubin level of the neonates on admission was found to be significantly lower than at discharge $(3.43 \pm 2.34$ vs. $13.76 \pm 8.04 \mathrm{p}=0.01)$.
The three management strategies that had been commonly used in the management of neonatal jaundice are medication, phototherapy and exchange blood transfusion. In the current study, all these strategies were adopted; all the neonates were placed on drugs and phototherapy whereas only about a quarter had exchange blood transfusion performed. Olusanya, et al. [6] submitted that a number of neonatal jaundice incidences in Nigeria required phototherapy and/or exchange blood transfusion (EBT), which according to them, is probably one of the highest rates globally.

From the results, three out every 20 neonates admitted to the hospital for neonatal jaundice during the period reviewed, had one complication or more. Results also showed that 25 neonates representing $69.4 \%$ of those with one complication or the other, died. This supports the submissions of a previous study [15] that neonatal jaundice is also a common paediatric problem associated with high morbidity and mortality. Also, various previous researchers had isolated neonatal jaundice as one of the significant causes of morbidity and mortality among neonates $[5,616,17,18,19,20,21,22]$. In a study by Iskander et al., $60.3 \%$ of the neonate admitted for neonatal jauindice were diagnosed for kernicterus, some of the neonate died [23].

\section{CONCLUSIONS}

The findings of this study reveal that more male neonates were admitted for neonatal jaundice than female, and the mean serum bilirubin level of the neonates decreased on discharge. A number of the neonates were also observed to develop one or more complications.

Implications for Nursing Practice. The results of this study revealed that neonatal jaundice affects a number of neonates; therefore, the efforts of nurses should be directed at three levels of prevention:

1) primary prevention - should be directed at educating the population, especially women of child bearing age, about neonatal jaundice, its predisposing factors and how to manage it;

2) secondary level of prevention - should involve nurses promptly rendering nursing care to all neonates with jaundice to prevent complications. Nurses should advocate for provision of phototherapy in our hospitals to provide prompt care. Nurses should conduct a thorough assessment on neonates and educate the mothers on how to detect neonatal jaundice so that they can detect any case on time;

3) tertiary prevention - should entail managing any complication promptly, this is important because in the current study a high incidence was found of acute bilirubin encephalopathy and jaundice-related deaths.

\section{REFERENCES}

1. Sarici SU, Serdar MA, Korkmz A. Incidence, course and prediction of hyperbilirubinaemia in near term and term newborns. Paediatrics. 2004; 113: 775-780

2. Newman TB, Xiong B, Gonzales VM, Escobar GJ. Prediction and prevention of extreme neonatal hyperbilirubinemia in a mature health maintenance organization. Arch Pediat Adolescent Med. 2000; 154: 1140-1147.

3. Watchko JF. Identification of neonates at risk for hazardous hyperbilirubinemia: emerging clinical insights. Pediatric Clin North Am. 2009; 56: 671-687. 
4.Liu X, Wang L, Stallones L, Wheeler KK, ZhaoW, Smith GA, Xiang H. Back pain among farmers in a northern area of China. Spine 2012; 37: 508-514.

5. Maisels MJ. Neonatal hyperbilirubinemia and kernicterus-not gone but sometimes forgotten. Early Hum Dev. 2009; 85(11): 727-732. doi: 10.1016/j.earlhumdev.2009.09.003 PMID: 19833460

6. Olusanya BO, Akande AA, Emokpae A, Olowe SA. Infants with severeneonatal jaundice in Lagos, Nigeria: incidence, correlates and hearingscreening outcomes. Trop Med Int Health. 2009; 14(3): 301-310.

7.Hameed NN, Na' Ma AM, Vilms R, Bhutani VK. Severe neonatal hyperbilirubinemia and adverseshort-term consequences in Baghdad, Iraq. Neonatology 2011; 100: 57-63. doi: 10.1159/000321990 PMID:21212697

8. Sgro M, Campbell D, Barozzino T \& Shah V. Acute neurological findings in a national cohort of neonates with severe neonatal hyperbilirubinemia. J Perinat. 2011; 31: 392-396.

9. Bhutani VK, Zipursky A, Blencowe H, Khanna R, Sgro M, et al. Neonatal hyperbilirubinemia andRhesus disease of the newborn: incidence and impairment estimates for 2010 at regional and globallevels. Pediatr Res. 2013; 74 Suppl 1: 86-100. doi: 10.1038/pr.2013.208 PMID: 24366465

10. Scrafford CG, Mullany LC, Katz J, Khatry SK, LeClerq SC, Darmstadt GL, Tielsch JM. Incidence of and risk factors for neonatal jaundice among newborns in southern Nepal. Trop Med Int Health. 2013; 18(11): 1317-28. doi: 10.1111/tmi.12189

11. Slusher TM, Zamora TG, Appiah D, Stanke JU, Strand M, et al. Global burden of severe neonatalhyperbilirubinemia: a systematic review and meta-analysis. JAMA Pediatrics (under review). 2014. doi:10.1001/ jamapediatrics.2014.2898 PMID: 25546699

12. Owa JA, Ogunlesi TA. Why we are still doing so many exchange blood transfusion for neonatal jaundice in Nigeria. World J Pediatr. 2009; 5: $51-55$.
13. Onyearugha CN, Onyire BN, Ugboma HAA. Neonatal jaundice Prevalence and associated factors as seen in Federal Medical Centre Abakaliki, Southeast Nigeria. J Clin Med Res. 2011; 3(3): 40-45. Available online http://www.academicjournals.org/JCMR

14. Coulter JBS, Akpabio MA, Jikeme MA, Kay T. Neonatal Jaundice in Northern Nigeria. Nig J Paediatr. 1978; 5: 12-5.

15. Abu-Ekteish F, Daoud A, Rimawi H, Kakish K, Abu-Heija A. Neonatal exchangetransfusion: a Jordanian experience. Ann Trop Paediatr. 2000; 20(1): 57-60

16. Jirapaet K. Thai healthy newborns have a higher risk. J Med Assoc Thai. 2005; 88(9): 1314-1318.

17. Ogunlesi TA, Dedeke IO, Adekanmbi AF, Fetuga MB, Ogunfowora $\mathrm{OB}$. The incidence and outcome of bilirubin encephalopathy in Nigeria: abi-centre study. Niger J Med. 2007; 16(4): 354-359.

18. Salas AA, Mazzi E. Exchange transfusion in infants with extreme hyper bilirubinemia: an experience from a developing country. Acta Paediatr. 2008; 97(6): 754-758.

19. Sanpavat S. Exchange transfusion and its morbidity in ten-year period at King Chulalongkorn Hospital. J Med Assoc Thai. 2005; 88(5): 588-592.

20. Tikmani SS, Warraich HJ, Abbasi F, Rizvi A, Darmstadt GL, Zaidi AK. Incidence of neonatal hyperbilirubinemia: a population-based prospective study in Pakistan. Trop Med Int Health. 2010; 15(5): 502507.

21. Olusanya BO. Letter to the editors: the burden of neonatal jaundice and sepsis in developing countries. Trop Med Int Health 2006; 11(3): 381.

22. Slusher T, Zipursky A, Bhutani VK. A global need for affordable neonatal jaundice technologies. Semin Perinatol. 2011; 35(3): 185-191.

23. Iskander I, Gamaleldin R, El Houchi S, El Shenawy A, Seoud I, El Gharbawi N, et al. Serum bilirubin and bilirubin/albumin ratio as predictors of bilirubin encephalopathy. Pediatrics 2014; 134: e1330-e1339. 